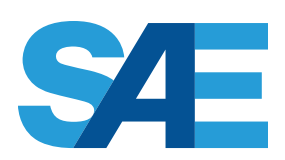

INTERNATIONAL

\title{
Experimental and Numerical Investigation of Ethanol/Diethyl Ether Mixtures in a CI Engine
}

\section{Vedharaj Sivasankaralingam, Vallinayagam Raman, Mohammed Jaasim Mubarak Ali, and Adamu Alfazazi \\ KAUST}

\section{Tianfeng Lu}

Univ of Connecticut

\author{
Hong Im, S. Mani Sarathy, and Robert Dibble \\ KAUST
}

CITATION: Sivasankaralingam, V., Raman, V., Mubarak Ali, M., Alfazazi, A. et al., "Experimental and Numerical Investigation of Ethanol/Diethyl Ether Mixtures in a CI Engine," SAE Technical Paper 2016-01-2180, 2016, doi:10.4271/2016-01-2180.

Copyright (C) 2016 SAE International

\begin{abstract}
The auto-ignition characteristics of diethyl ether (DEE)/ethanol mixtures are investigated in compression ignition (CI) engines both numerically and experimentally. While DEE has a higher derived cetane number (DCN) of 139, ethanol exhibits poor ignition characteristics with a DCN of 8. DEE was used as an ignition promoter for the operation of ethanol in a CI engine. Mixtures of DEE and ethanol (DE), i.e., DE75 (75\% DEE + 25\% ethanol), DE50 $(50 \% \mathrm{DEE}+50 \%$ ethanol $)$ and DE25 (25\% DEE $+75 \%$ ethanol), were tested in a CI engine. While DE75 and DE50 auto-ignited at an inlet air pressure of 1.5 bar, DE25 failed to auto-ignite even at boosted pressure of 2 bar. The peak in-cylinder pressure for diesel and DE75 were comparable, while DE50 showed reduced peak in-cylinder pressure with delayed start of combustion (SOC). Numerical simulations were conducted to study the engine combustion characteristics of DE mixture. A comprehensive detailed chemical kinetic model was created to represent the combustion of DE mixtures. The detailed mechanism was then reduced using standard direct relation graph (DRG-X) method and coupled with 3D CFD code, CONVERGE, to simulate the experimental data. The simulation results showed that the effects of physical properties on DE50 combustion are negligible. Simulations of DE50 mixture revealed that the combustion is nearly homogenous, while diesel (n-heptane used as a surrogate) and DE75 showed similar combustion behavior with flame liftoff and diffusion controlled combustion. Diesel exhibited auto-ignition at an equivalence ratio of 2 , while DE75 and DE50 showed auto-ignition in the equivalence ratio range of 1-1.5 and 0-1, respectively. The experiments and numerical simulations demonstrate how the high reactivity of DEE supports the auto-ignition of ethanol, while ethanol acts as a radical scavenger.
\end{abstract}

\section{Introduction}

Amongst several types of biofuels, ethanol has evolved as a suitable alternate fuel for engine applications $[\underline{1}, \underline{2}]$. Ethanol, a bio-derived fuel, is a two carbon alcohol with amenable fuel properties $[\underline{3}, \underline{4}, \underline{5}]$ and there is an impetus to blend more ethanol into petroleum fuels. Its use is legislated in many countries under renewable fuel standards. Gasoline in the US has 10\% ethanol and its use has become prevalent. The Environmental Protection Agency (EPA) has recommended E10 and E15 for automotive gasoline vehicles [ $[\underline{6}, \underline{7}]$. The use of $85 \%$ ethanol with gasoline (E85) is available for flexible fuel vehicles (FFV) [ㅁ, $\underline{9}]$.

While utilization of ethanol in spark ignition (SI) engines is widespread, it could be a fuel for compression ignition (CI) engines [10]. Since the cetane number of ethanol is low, the ignition characteristics of ethanol are poor and the use of ethanol in CI engine has many limitations [11]. In order to improve the ignition characteristics of ethanol in CI engines, it is used in blends with diesel. There have been a number of studies on the investigation of performance, combustion and emission characteristics of ethanol blended with diesel for $\mathrm{CI}$ engine $[\underline{12}, \underline{13}, \underline{14}, \underline{15}]$. In summary, most research declares a significant reduction in gaseous emissions with an improvement in brake thermal efficiency (BTE) for ethanol in diesel. However, when the proportion of ethanol in diesel exceeds a certain limit, engine knock is observed due to longer ignition delay period [16]. For maximum use of ethanol in CI engine, a dual-fuel mode of operation may be used, wherein the less reactive fuel (ethanol) is injected in the port and high reactive fuel (diesel) is injected directly into the cylinder [17]. By adjusting the fuel injection timing, maximum amount of diesel can be replaced by ethanol [1]․ With 
regards to emissions, premixed combustion of ethanol amounts to increased $\mathrm{CO}$ and $\mathrm{HC}$ emissions, while $\mathrm{NO}_{\mathrm{X}}$ and smoke emissions are simultaneously reduced [18].

Investigation of ethanol in blend or dual fuel mode in CI engine is well established [17]. Attempts to use pure ethanol in CI engine by modifying the engine design have been made by several research groups $[19,20]$. Under the homogeneous charge compression ignition (HCCI) mode, ethanol was port-injected by varying the intake air temperature from $120^{\circ} \mathrm{C}$ to $150^{\circ} \mathrm{C}$ at different equivalence ratios [21] . Besides HCCI operation, ethanol can also be used in CI engine under partially premixed compression ignition (PPCI) mode [22, 23] .

Recently, Scania leveraged the benefits of ethanol by operating it in a $\mathrm{CI}$ engine under diesel like fuel injection conditions (Direct injection) at a higher compression ratio (CR) of 28 [24]. Even with this high $\mathrm{CR}$, it was still necessary to add $5 \%$ of ignition promoters [25]. In another study, it was reported that $10 \%$ ignition promoter (glycerol ethoxylate) was required to improve the startup characteristics of the engine at a CR of 28 while using ethanol [26]. Thus, even with the engine modification, ignition promoters are required to facilitate the auto-ignition of ethanol in CI engine.

Ethers such as diethyl ether (DEE) and dimethyl ether (DME) are also considered as potential ignition promoters [27]. DEE is a liquid fuel and when compared to DME, fuel handling and storage are convenient [28]. DEE by itself is a fuel and could be blended in any proportion with ethanol unlike other ignition promoters. In this respect, Mack et al [29] utilized DEE as an ignition promoter for ethanol and the resultant DEE - ethanol (DE) mixtures was operated in HCCI mode. They demonstrated preferential combustion of DE mixture, as the reactivity of DEE is higher. The operation of DE mixture does not require engine modifications unlike other ignition promoters. As DEE can be easily produced from ethanol, these DE fuels for CI engine are essentially ethanol-derived fuels.

In this study, as a first step, we select the fuel as ethanol and the additive as the ether of ethanol, DEE. While the operation of DE mixtures in HCCI mode was studied, rare attention is paid to investigate the engine characteristics under direct injection mode. Therefore, an attempt has been made to study the auto-ignition characteristics of DE mixtures in a CI engine at diesel like fuel injection conditions, and the combustion results are compared with diesel. Further, to improve the fundamental understanding on spray and auto-ignition, numerical simulations of these DE mixtures were performed using a 3D CFD code, CONVERGE. A new chemical kinetic model for DEE and ethanol was developed with comprehensive low temperature chemistry for DEE. The developed model was reduced, and the reduced model was coupled with CFD code. Finally, the model was validated against engine experimental data and a better understanding on the evaporation and auto-ignition behavior of ethanol using DEE is presented.

\section{Methodology}

\section{Test Fuels and Properties}

The physical and thermal properties of DEE and ethanol are compared with US NO. 2 diesel in Table 1. DEE and ethanol have lower viscosity, boiling point and flash point than diesel. The higher cetane number of DEE shows that it may be used as a potential ignition promoter. On the other hand, the ignition characteristics of ethanol are poor; ethanol has a low cetane number. Also, the higher latent heat of vaporization of ethanol produces a charge cooling effect that further retards the ignition of ethanol.

Table 1. Chemical composition, thermo-physical and chemical properties of diesel, ethanol and diethyl ether

\begin{tabular}{|l|c|c|c|c|}
\hline Property & $\begin{array}{c}\text { Measurement } \\
\text { methods }\end{array}$ & $\begin{array}{c}\text { US NO. 2 } \\
\text { Diesel }\end{array}$ & Ethanol & $\begin{array}{c}\text { Diethyl } \\
\text { ether }\end{array}$ \\
\hline Density $\left(\mathrm{kg} / \mathrm{m}^{3}\right)$ & $\begin{array}{c}\text { ASTM } \\
\text { D1298 }\end{array}$ & 843 & 789 & 720 \\
\hline Viscosity $\left({ }^{*} 10^{-6} \mathrm{~m}^{2} / \mathrm{s}\right)$ & ASTM D445 & 2.3 & 1.2 & 0.2 \\
\hline Boiling point $\left({ }^{\circ} \mathrm{C}\right)$ & ASTM D86 & $180-300$ & 78 & 35 \\
\hline Flash point $\left({ }^{\circ} \mathrm{C}\right)$ & ASTM D93 & 69 & 13 & -45 \\
\hline $\begin{array}{l}\text { Lower heating value } \\
(\mathrm{MJ} / \mathrm{kg})\end{array}$ & $\begin{array}{c}\text { ASTM } \\
\text { D5865 }\end{array}$ & 45.6 & 26.8 & 33.9 \\
\hline H/C (molar ratio) & Calculated & 1.75 & 3 & 2.5 \\
\hline $\begin{array}{l}\text { O/C (molar ratio) } \\
\text { Calculated }\end{array}$ & 0 & 0.5 & 0.25 \\
\hline Derived cetane number & $\begin{array}{c}\text { ASTM } \\
\text { D6890 }\end{array}$ & 48 & 8 & 139 \\
\hline $\begin{array}{l}\text { Latent heat of } \\
\text { vaporization (kJ/kg) }\end{array}$ & $\begin{array}{c}\text { Literature } \\
{[30]}\end{array}$ & 250 & 840 & 350 \\
\hline $\begin{array}{l}\text { Stoichiometric air }- \\
\text { fuel ratio }\end{array}$ & \begin{tabular}{c} 
Calculated \\
\hline
\end{tabular} & 14.7 & 9 & 11 \\
\hline
\end{tabular}

The extremely opposite nature of DEE and ethanol with respect to ignition are expected to counteract each other when they are blended to form DE mixture. For CI engine testing, DEE is blended to ethanol in following proportions: DE75 (75\% DEE $+25 \%$ ethanol), DE50 $(50 \%$ DEE $+50 \%$ ethanol $)$ and DE25 (25\% DEE $+75 \%$ ethanol). The derived cetane number (DCN) of these mixtures is measured in an ignition quality tester (IQT) based on ASTM D6890. An IQT, a constant volume combustion chamber, was used to measure the ignition delay time for different fuels. From the measured ignition delay time, DCN was estimated using a standard correlation prescribed in the standard [31]. The measured DCN and other fuel properties for DE75, DE50 and DE25 are shown in Table 2.

Table 2. Fuel properties of DE75, DE50 and DE25

\begin{tabular}{|l|c|c|c|}
\hline Property & DE75 & DE50 & DE25 \\
\hline Density $\left(\mathrm{kg} / \mathrm{m}^{3}\right)$ & 738 & 755 & 772 \\
\hline Viscosity $\left(* 10^{-6} \mathrm{~m}^{2} / \mathrm{s}\right)$ & 0.5 & 0.7 & 0.9 \\
\hline Lower heating value $(\mathrm{MJ} / \mathrm{kg})$ & 32.3 & 30.4 & 28.6 \\
\hline Derived cetane number & 57 & 24 & 9 \\
\hline
\end{tabular}

\section{Engine Experimental Set Up and Arrangement}

A single cylinder CI engine coupled with an eddy current dynamometer was used for testing DE mixtures. The detailed specifications of the engine are shown in Table 3. The electronic control unit (ECU) controls the amount of fuel to be injected, fuel 
injection timing, fuel injection pressure and valve timing. AVL Puma software aids in data acquisition and records engine parameters such as torque, IMEP, brake power, inlet manifold pressure and temperature, coolant and lubrication oil temperature. The fuel and airflow rate are measured using AVL735/753 fuel balance meter and air flow meter, respectively. A piezo electric pressure transducer fitted in the cylinder head measures the in-cylinder pressure through AVL indicom software. The pressure data was recorded for 300 cycles and the cycle that has its IMEP equal to the average IMEP, was chosen for combustion analysis. The recorded pressure signals were used for the estimation of other combustion parameters such as pressure rise rate, heat release rate and ignition delay. More details about the engine instrumentation can be found in Cha et al [32].

\section{Experimental Methodology}

In the past, DEE was added to vegetable oil and the resultant mixture was operated in a CI engine $[\underline{33}, \underline{34}]$. When DEE was added to vegetable oil, the viscosity of the resultant blend was reduced and used as a drop-in fuel for diesel. Thus, operation of pure biofuel in CI engine was possible with obviously a few limitations, as CI engines are standardized for the operation of diesel. In the current study, DEE was used to support the auto-ignition of ethanol to enable compression ignition of ethanol in CI engine. DEE readily blended with ethanol and operation of pure biofuel in CI engine was realized. However, the highly reactive DEE damaged the fuel lines made of rubber and then the contaminated fuel clogged the fuel injector. After certain period of operation, the fuel injector could not inject DE mixtures into the cylinder and thus the engine stalled. To counteract this clogging problem, the rubber fuel lines from the tank through the filter and pump to common rail were replaced by Teflon tubing. The modification with the replacement of rubber fuel lines with Teflon tubing is straight forward and inexpensive

Both DEE and ethanol have lower viscosity than diesel and are generally categorized as light or thinner biofuels. Normally, use of less viscous fuels in CI engine is prone to cause injector leak or pump wear. When DE mixtures are used in CI engine under direct injection mode at a normal fuel injection timing of -20 crank angle degree (CAD), there could be pressure loss inside injector sac due to the injector back pressure. The injector suffered from back leakage and the fuel pump could not build the require pressure for normal engine operation. After a thorough analysis of the fuel injection system, the problem with injector backpressure was recognized. To prevent the above reported problem, the fuel injection system requires adequate lubrication. As such, 500ppm of Lubrizol 539M was added to DE mixtures before testing in $\mathrm{CI}$ engine and lubrication failure was averted, ensuring the normal operation of engine.

The DE mixtures were tested in the reported CI engine at a speed of $1250 \mathrm{rpm}$ under different loading conditions (IMEP $=1$ to 6 bar) and the results are compared with diesel. The engine was operated at a fuel injection pressure of 300 bar and fuel injection timing of -20 CAD. Though the common rail fuel injection system can go up to 2000 bar, a low fuel injection pressure is maintained for the current study to enable the operation of less viscous fuels like DEE and ethanol. The inlet air pressure and temperature were maintained at 1.5 bar and $25^{\circ} \mathrm{C}$, respectively, for all the engine experiments. All the measurements were done once the engine has attained a steady state condition.
Table 3. Single cylinder CI engine specifications

\begin{tabular}{|l|l|}
\hline Engine Type & AVL 5402 DI2 \\
\hline No. of cylinders & 1 \\
\hline Bore (mm) & 85 \\
\hline Stroke (mm) & 90 \\
\hline Swept Volume (cm3) & 511 \\
\hline Compression Ratio & 17 \\
\hline Air Intake System & Turbocharged \\
\hline Valve Type & DOHC \\
\hline Number of valves & 2 -intake 1-exhaust \\
\hline Coolant Temperature & $80^{\circ} \mathrm{C}$ \\
\hline Lubricant Temperature & $80^{\circ} \mathrm{C}$ \\
\hline
\end{tabular}

\section{Computational Modeling}

\section{Chemical Kinetics}

A chemical kinetic model for DE mixtures was developed for the improved understanding of ignition enhancers to ethanol. The model was built in a hierarchical manner [ $[\underline{5}$ ] starting with the Aramco Mech $1.3 \mathrm{C}_{0}-\mathrm{C}_{4}$ base chemistry from Metcalfe et al. [ㅌ5]. The ethanol sub-mechanism was updated with that of Mittal et al. [주․ When the Aramco Mech was combined with ethanol and DEE, predictions were far off. Satisfactory agreement was achieved with substantial low temperature chemical reaction additions to the comprehensive DEE sub-mechanism, as discussed below. Yasunaga et al. [그, 38] presented a DEE chemical kinetic model for high temperature pyrolysis and oxidation conditions. Werler et al. [39] later validated the model against high temperature shock tube measurements and made modifications to rates of hydrogen abstraction by $\mathrm{HO}_{2}$ radicals to better predict their data. The aforementioned experimental studies on DEE focused primarily on high temperature conditions (i.e., above $1000 \mathrm{~K}$ ). The DEE model was not validated under lower temperature conditions of relevance to CI engine ignition. Therefore, we started with the high temperature kinetic model from Yasunaga et al. [구,$\underline{38}]$ with the modifications suggested by Werler et al. [39]. The low temperature reaction classes and related rate constants were added by analogy to the comprehensive di-butyl ether (DBE) kinetic model developed by Cai et al. [40]. The rate constants for the scission of CO bonds in ethanol and its radicals were adopted from the theoretical calculations of Al Rashidi et al. [41]. Finally, reactions between ethyl peroxy radicals and DEE were added, as these were cited as important in the DEE low temperature oxidation chemistry study by Di Tommaso et al. [42]. All simulations were performed with commercial software using the constant volume homogenous batch reactor model [푸].

The newly developed chemical reaction mechanism for DEE and ethanol encompasses 1916 reactions and 348 species. In order to reduce the computational time, the developed mechanism was reduced using the method of direct relation graph with expert 
knowledge (DRG-X) [44]. This method is based on the observation that some species are weakly coupled to others and do not have significant roles in overall combustion processes, and thus they can be removed from the mechanism. However, unlike the original DRG method that is restricted by a uniform error tolerance for all species, DRG-X allows to separately control the errors for species of interest. Therefore, this method results in a smaller skeletal mechanism with similar chemical fidelity as compared to DRG method. In this work, the detailed mechanism is reduced by specifying the error tolerance for heat release as 0.2 . The error tolerance for $\mathrm{H}, \mathrm{OH}$, and $\mathrm{HO}_{2}$ radicals is $0.5,0.3$ and 0.5 respectively, while the default error tolerance for other species is 0.9 . A skeletal mechanism with 88 species and 470 reactions was generated.

\section{Numerical Simulation}

Numerical modeling was performed using CONVERGE, a 3D CFD code. Physical properties of DEE and ethanol such as surface tension, viscosity, density, enthalpy, critical temperature and boiling point as a function of temperature were incorporated to mimic the spray and evaporation of the fuel droplets. KH-RT spray model [45] was used to simulate the spray breakup process. The droplets were assumed to coalesce and disperse during the breakup processes. The Rosslin - Rammler cumulative probability distribution was used to determine the droplet distribution inside the computational domain and all the droplets were assumed to have spherical shape. The Frossling droplet evaporation correlation was used to account for the droplet evaporation [46], which uses the fuel properties at various temperatures. The Reynolds-averaged turbulence model (RANS) based on RNG k-epsilon was used to model the turbulence inside the domain. The SAGE multi-zone combustion model [47] was used to compute the chemical source terms by mapping the grid cells to the temperature bins of $5 \mathrm{~K}$ and $\varphi$ bins of 0.05 increments. Other physical sub-models follow the standard built-in capabilities in CONVERGE v2.3 [뇨] . The Chalmers University n-heptane reduced gas phase kinetics was used for diesel combustion [무] .

The mesh used in the current study is shown in Figure 1. The base grid is the initial grid that is generated during the run time by CONVERGE. For the current simulation, a base grid size of $4 \mathrm{~mm}$ was used in all three directions. Level 4 adaptive mesh refinement (AMR) was employed, which works based on the conditions provided to refine the grid. Herein, the grid was refined based on velocity and temperature changes inside the combustion domain. Further, level 4 nozzle embedding was provided to capture the near spray events with higher accuracy. The resulting cell size in all three directions is calculated based on the standard formulation (cell size $=$ Base grid size $/ 2^{\mathrm{n}}$ ), where $\mathrm{n}$ is the level of refinement provided. The current value for base grid size and cell refinement was used after a thorough testing to provide grid-independent solution.

The fuel injection timing, fuel injection pressure and fueling quantity from the engine experimental study were given as input for the CONVERGE simulation. The desired inlet air pressure and temperature that enables auto ignition of DE mixtures are also provided as input parameters for the CONVERGE simulation. Further, all the engine simulations were performed for diesel and DE mixtures at an engine speed of $1250 \mathrm{rpm}$ and IMEP of 4 bar. Initially, motored simulations were carried out and blow-by in the engine was accounted for by reducing the compression ratio from 17 to 16.6 based on the recommendations reported in [ $\underline{50}]$. The experimental motor pressure trace was first matched to get more reliable results, which were then coupled with spray and turbulence model in the present study

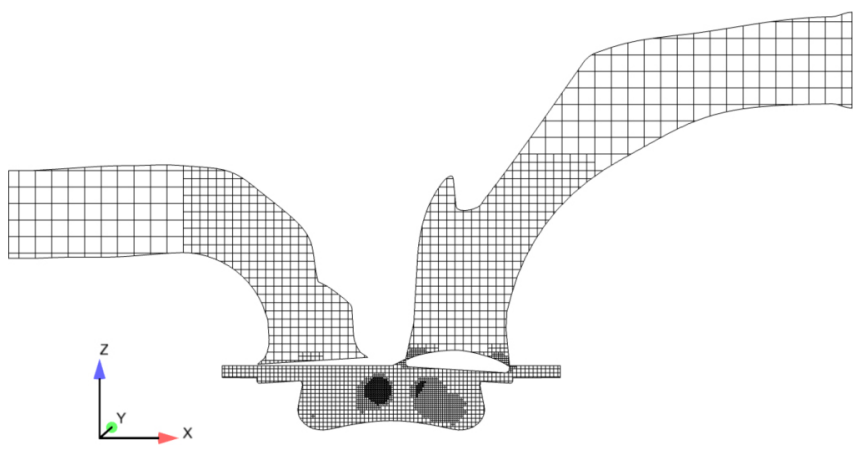

Figure 1. Mesh geometry of the computational domain used in the numerical study

\section{Results and discussion}

\section{Experimental study of DE mixtures in a CI engine}

Amongst the different DE mixtures, DCN of DE75 is higher than that of diesel, so that no boosted intake pressure was necessary for the operation of DE75 in a CI engine. However, the observed lower DCN for DE50 and DE25 would hinder their auto ignition. In this regard, the inlet air pressure $\left(\mathrm{P}_{\text {in }}\right)$ and temperature of the engine were increased from 1 bar to 2 bar and $25^{\circ} \mathrm{C}$ to $100^{\circ} \mathrm{C}$, respectively, in steps of 0.5 bar and $25^{\circ} \mathrm{C}$. From the $\mathrm{CI}$ engine experiments, autoignition of DE25 was not realized for all $\mathrm{P}_{\text {in }}$ and temperature conditions under study. Similarly, the auto-ignition for DE50 was not possible at $\mathrm{P}_{\text {in }}=1$ bar, but stable combustion was attained at $1.5 \mathrm{bar}$ at all temperatures. Therefore, combustion characteristics for DE50, DE75 and diesel were analyzed at the same operating conditions, i.e. $\mathrm{P}_{\text {in }}=1.5$ bar and temperature of $25^{\circ} \mathrm{C}$.

The variation of in-cylinder pressure and heat release rate with respect to crank angle for DE mixtures are shown in Figure 2 and $\underline{3}$, respectively. Although diesel and DE75 auto-ignite at all ranges of fuel injection timings, DE50 attained stable combustion only at an advanced injection timing of -20 CAD due to its lower DCN. When diesel was operated at same fuel injection timing, the start of combustion (SOC) was advanced with a shorter ignition delay (8 CAD), while ignition delay was longer for DE50 (23 CAD). Therefore, SOC for DE50 was after top dead center (TDC), and the peak in-cylinder pressure was observed to be lower. Furthermore, the pressure rise rate was lower for DE50 with a decrease in in-cylinder pressure by $25 \%$ compared to diesel and DE75. 


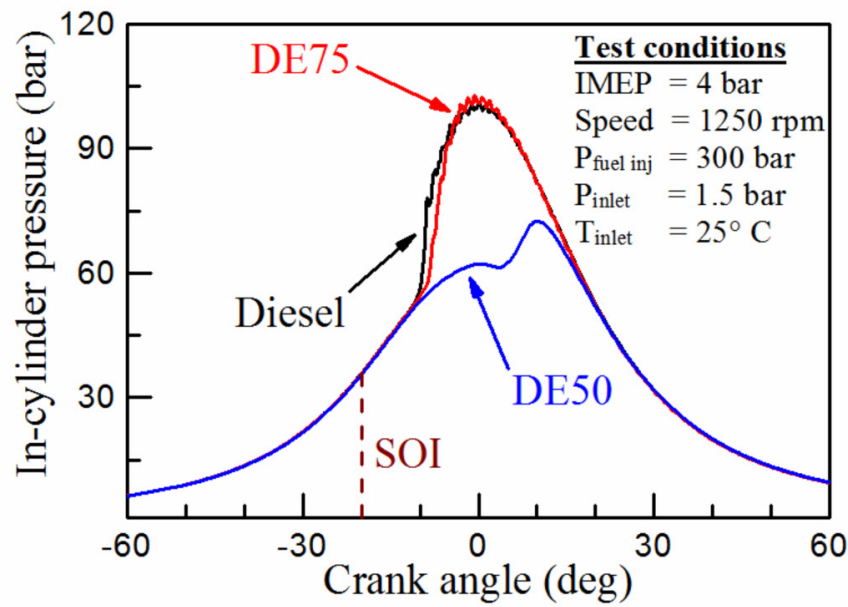

Figure 2. In-cylinder pressure for DE mixtures at IMEP of 4bar

A higher quantity of fuel was required to achieve similar IMEP in the case of DE mixtures, which is attributable to the lower heating value of DEE and ethanol compared to diesel. In comparison, the maximum heat release rate is lower for DE50 not only due to its lower heating value but also due to its longer ignition delay. Although DEE has a higher DCN and reactivity, the addition of ethanol supresses DEE auto-ignition due to its radical scavenging effect; the higher latent heat of vaporization of ethanol further postpones the combustion of ethanol enriched mixtures. Furthermore, the lower viscosity of DE mixtures lowers its bulk modulus, which delays the start of dynamic fuel injection timing. Contrary to the expectations based solely on its high DCN, the start of combustion was delayed for DEE. For example, DCN of DE75 is higher than diesel, but its ignition delay is 2 CAD later than diesel; this discrepancy is thus attributed to DE75's delayed fuel injection timing. This finding is in agreement with Rakopoulos et al. [51], wherein delayed SOC was observed for mixtures of DEE and diesel. Finally, the combustion duration, which is defined as the crank angle interval between $10 \%$ and $90 \%$ of fuel burnt, for diesel, DE75 and DE50 was 5.3 CAD, 4.1 CAD and 9.3 $\mathrm{CAD}$, respectively. Thus, for the same fuel injection timing, combustion duration is slightly shorter for DE75 compared to diesel and it is longer for DE50.

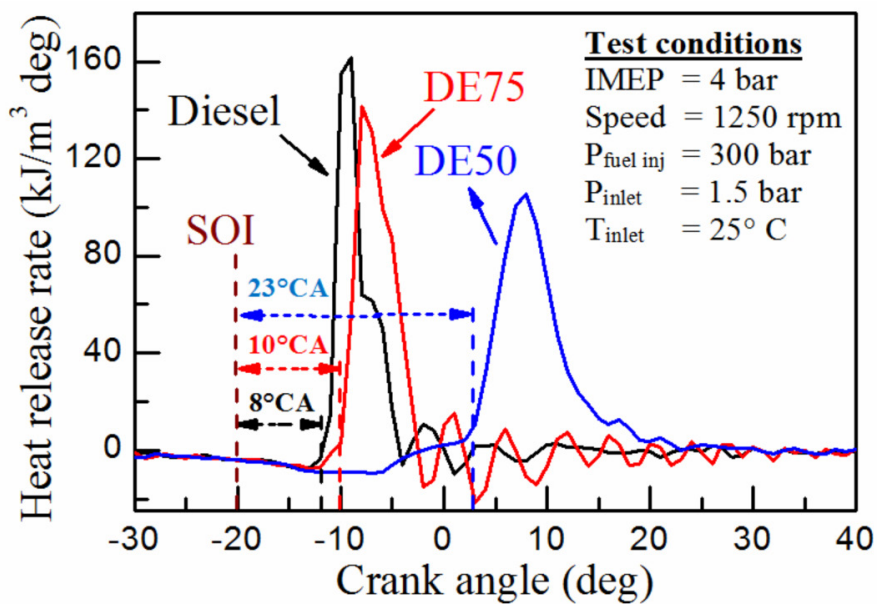

Figure 3. Heat release rate for DE mixtures at IMEP of 4 bar

Direct injection of DE mixtures in CI engine has not been explored before and this study has initiated an investigation on it. The lower vapor pressure of DEE is likely to cause vapor lock in fuel pumps (cavitation) and thus, new modified fuel injection system can be developed. In addition, this study reports the effect of highly reactive DEE on fuel lines and the inference of injector blocking clearly demonstrates it. Storing DEE in fuel tank could pose a problem and therefore, the stability of DE mixtures in tank has to be investigated in the future.

\section{Numerical Simulations of DE Mixtures in CI Engine}

To understand the behavior of DE mixture in CI engine and better explore the auto-ignition characteristics, a computational study was performed in addition to experimental investigation. The numerical results were compared with the experimental results to validate the accuracy of the developed model. Figure 4 shows the comparison of in-cylinder pressure trace from engine experiment and numerical simulation for DE mixtures. Diesel and DE75 have similar pressure curves and were anticipated to have same behavior inside the cylinder, which will be discussed later with spatial visualization of the combustion domain. The peak pressure, ignition delay and SOC of all DE mixtures match well with the experimental data. Thus, the inclusion of low temperature chemistry for DEE has captured the combustion phenomenon in CI engine, validating the numerical approach. Carbon attached to oxygen in DEE is loosely bonded and this leads to effective $\mathrm{H}$ abstraction; subsequent bimolecular reactions with $\mathrm{O}_{2}$ and intramolecular hydrogen migrations reactions eventually lead to the formation of highly reactive chain branching intermediates (peroxides). However, when the proportion of ethanol in DE mixture is higher, the radical formation via chain branching is suppressed due to scavenging effect by ethanol and this is reflected in the simulation results. Even in the numerical study, auto-ignition of DE25 could not be achieved, consistent with the experimental findings.

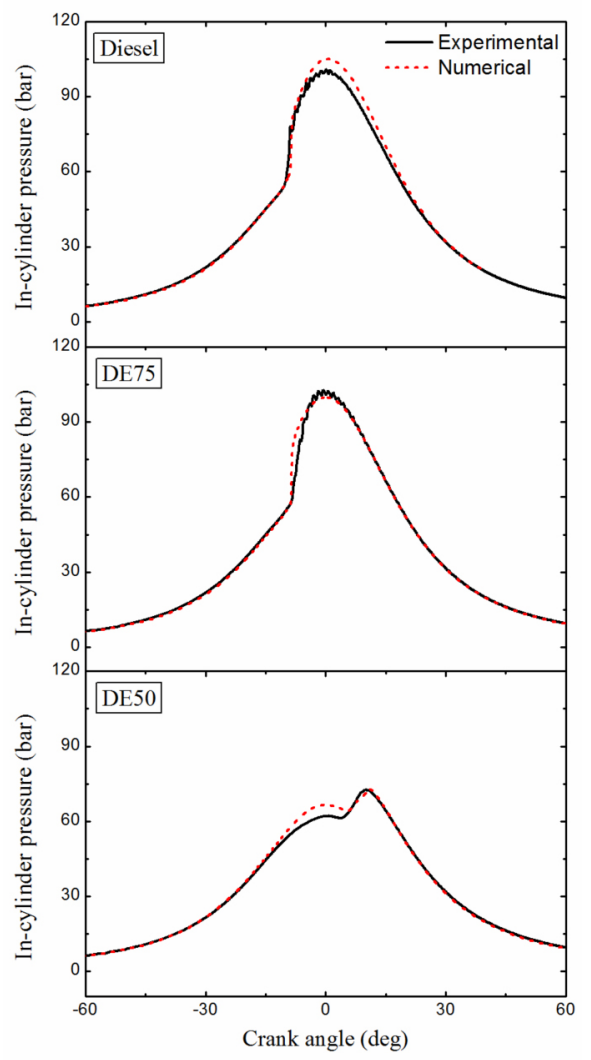

Figure 4. Comparison of experimental and numerical in-cylinder pressure curve for diesel, DE75 and DE50 at an engine speed of $1250 \mathrm{rpm}$ and IMEP $=4$ bar 
In addition to the chemical kinetics, the combustion behavior for DE mixtures is analyzed in terms of the physical property effects of the fuels. Since both DEE and ethanol have properties that are different from conventional diesel, it is rational to examine the spray and evaporation characteristics that precede combustion. The macroscopic spray behavior of different test fuels is investigated by analyzing the spray pattern from one nozzle tip. The distance from the nozzle tip until the portion of spray where it fades is regarded as spray tip penetration. Diesel has a longer spray tip penetration than other test fuels, which is obvious from Figure 5. Since diesel has a higher viscosity than DEE and ethanol, diesel forms larger droplets. With increased momentum for larger liquid droplet, the spray tip penetration is higher for diesel. On the other hand, DEE and ethanol are dispersed finer and the droplets formed are believed to be smaller. Therefore, the spray tip penetration for DE mixtures is shorter than diesel. These findings are consistent with previous studies with biodiesel and alcohol fuels [르, $\underline{53}]$.

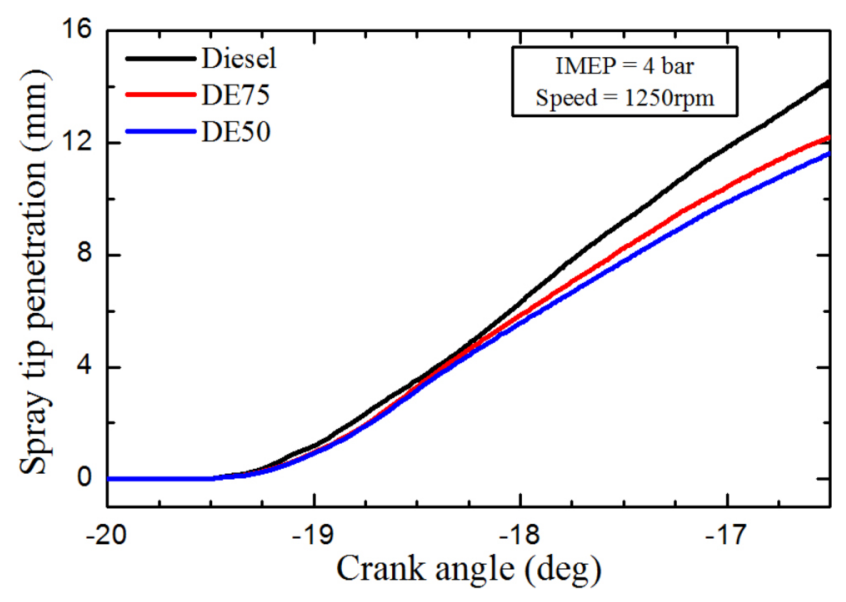

Figure 5. Spray tip penetration length for diesel, DE75 and DE50

The evaporation of fuel plays a major role in determining the accuracy of the simulation. The evaporation characteristics of different test fuels are elucidated from the plot of the vapor mass with respect to crank angle (Figure 6). At $-15 \mathrm{CAD}$, the total vapor mass of diesel is $5.1 \mathrm{mg}$, DE75 is $4.4 \mathrm{mg}$ and DE50 is $4.2 \mathrm{mg}$. The lower viscosity and boiling point of DEE and ethanol than diesel, is expected to increase the vapor mass for DE mixtures. However, the vapor mass is lower for DE mixtures as the heat of vaporization of ethanol is higher.

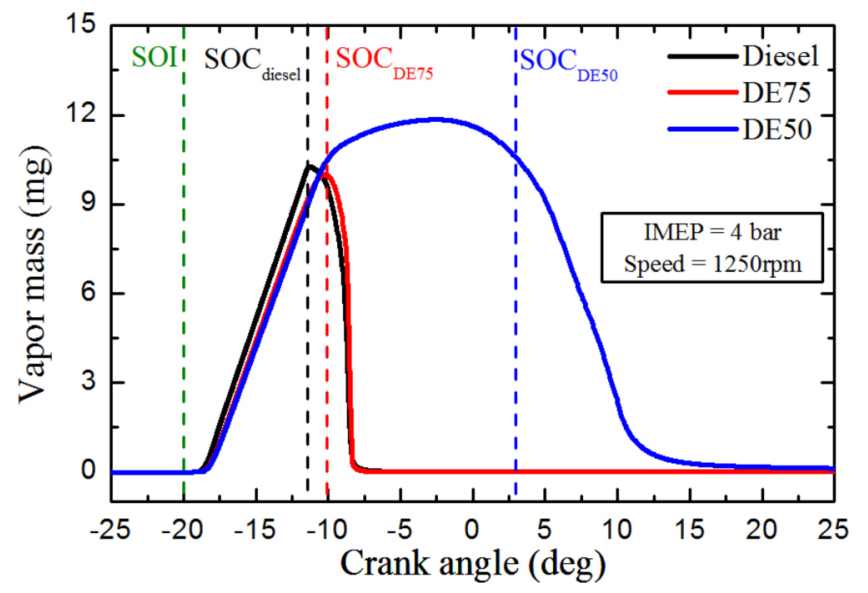

Figure 6. Vapor mass present in the combustion domain for diesel, DE75 and DE50
Due to different reactivity of diesel, DEE and ethanol, SOC is different for all test fuels and this further affects the vapor mass present in the combustion domain. The total vapor mass of DE50 is higher among all test fuels. DEE and ethanol have lower heating value; in order to produce same IMEP (4 bar), more amount of fuel is injected and thus the vapor mass is higher for DE50 than diesel. For diesel, the vapor mass spans from the point of fuel injection (-20 CAD) to $-8 \mathrm{CAD}$, which is $4 \mathrm{CAD}$ after SOC. On the other hand, DE50 still remains in vapor state at the same crank angle position, as the quantity of fuel injected is more and DCN is lower. The DE50 mixture ignited later, and thus more homogenous combustion is expected. DE75 shows comparable vapor fraction with diesel despite its lower heating value, as it ignites earlier due to its higher DCN. To better assess the vapor distribution in combustion domain, the vapor fraction contour at different stages of fuel evaporation and combustion is shown in Figure 7.

Mack et al [29] examined DEE and ethanol mixtures in a HCCI engine and reported that the combustion of DEE precedes that of ethanol due to the high reactivity of DEE. However, since only the HCCI combustion mode is considered in their study, the investigation of spray and evaporation of these fuels was not accounted for. In this study, since DE mixtures were injected directly into the cylinder, the fuel spray and evaporation would likely affect the combustion. In a measure to understand this phenomenon, the vapor mass fraction of DE50 was considered. The individual vapor fraction of DEE and ethanol present in the combustion domain was estimated for DE50 mixture and shown in Figure 8 .

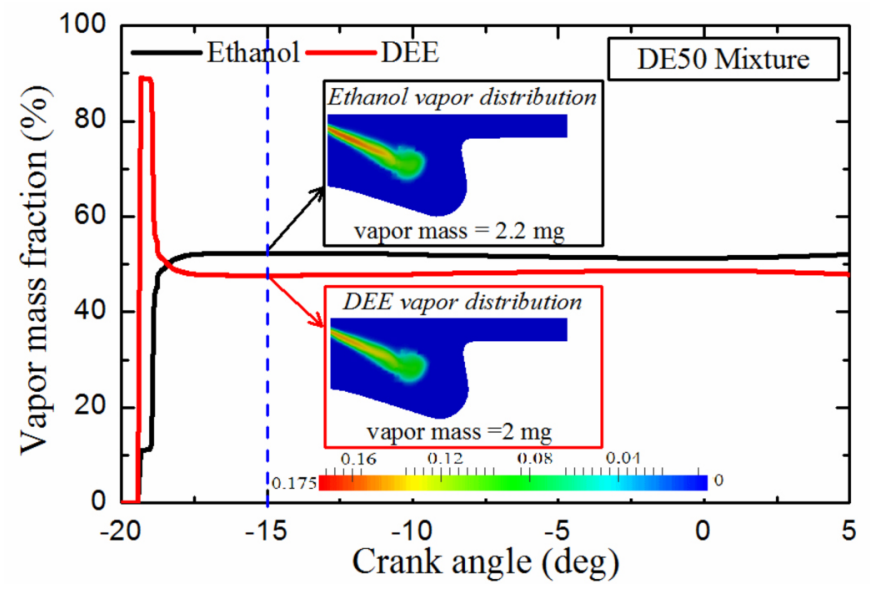

Figure 8. Individual vapor fraction of DEE and ethanol present in the combustion domain for DE50

Immediately after the start of fuel injection, the vapor mass fraction of both DEE and ethanol are observed to be same. The vapor mass of DEE and ethanol in DE50 at -15 CAD was $2 \mathrm{mg}$ and $2.2 \mathrm{mg}$, and 5.6 $\mathrm{mg}$ and $5.9 \mathrm{mg}$ at $0 \mathrm{CAD}$, respectively. Both ethanol and $\mathrm{DEE}$ evaporate at the same time and the formation of combustible air/fuel mixture follows. At the point of fuel injection, the temperature inside the combustion chamber is higher than the boiling point of both DEE and ethanol, so that both the fuel evaporates simultaneously. For better understanding of this behavior, the individual vapor mass fraction contour of DEE and ethanol, in DE50, is examined. The vapor mass fraction contour also show a similar distribution of both DEE and ethanol in DE50. This result implies that physical properties has little influence on the combustion for DE mixtures, and the auto-ignition of DE mixtures is mainly determined by the chemical 
kinetics. The chemical reactivity is more pronounced for DEE due to its higher DCN, but ethanol suppresses auto-ignition of the bulk mixture due to its radical scavenging effect.

Volume rendering of in-cylinder temperature for all test fuels at SOC is shown in Figure 9. It indicates that lifted flame is observed for diesel and DE75, whereas no lifted flame is observed for DE50.
Diffusion flames are clearly visible for diesel with a lift off length, whereas the flame is very close to the injection location for DE75 with smaller lift off length. Spray combustion is evident for diesel and DE75, whereas DE50 show near homogeneous or stratified combustion. Thus, it can be hypothesized here that diesel and DE75 will have similar combustion characteristics, while DE50 is different.
Crank angle

(deg)

$-15$

$-10$

$-5$

0
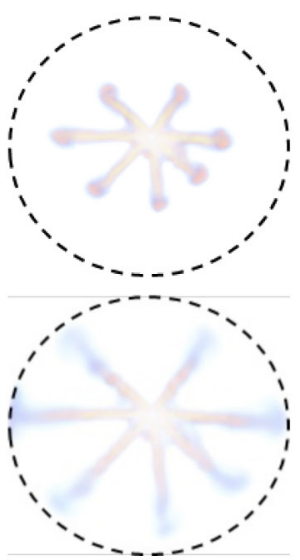

DE75
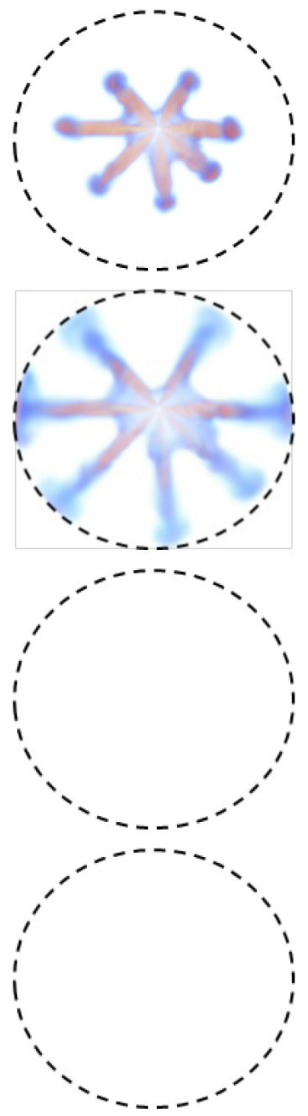

DE75
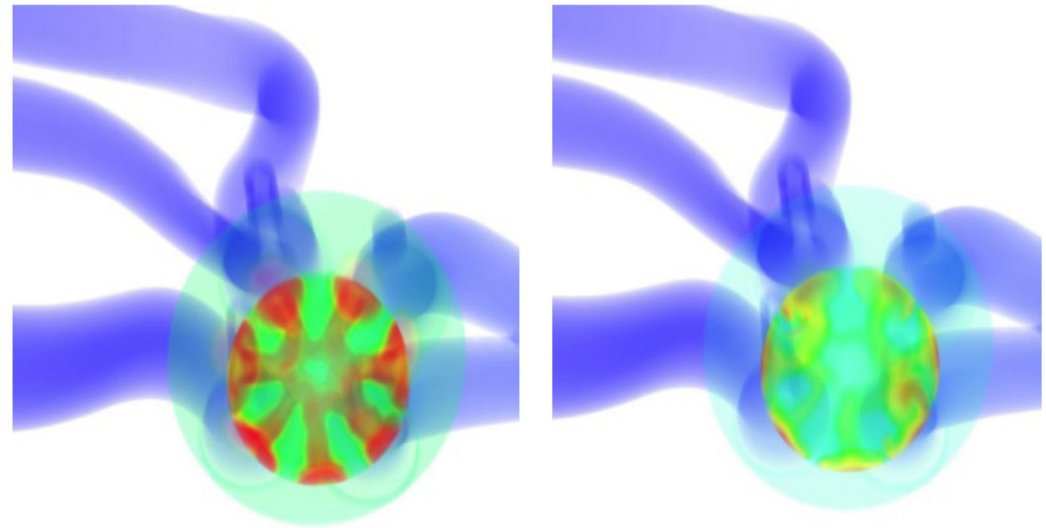

$\mathrm{SOC}=3 \mathrm{CA}$

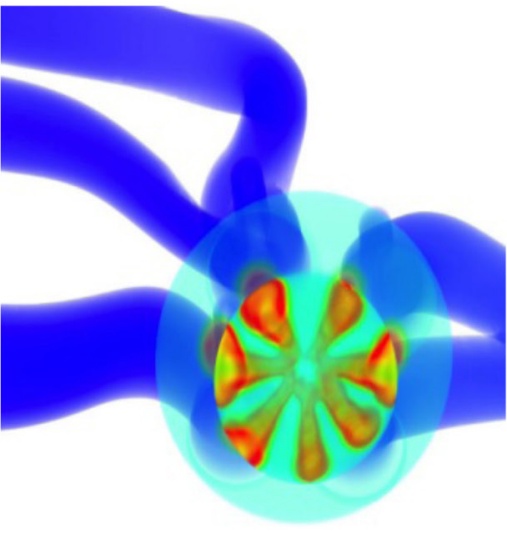

$\mathrm{SOC}=-12 \mathrm{CA}$
$\mathrm{SOC}=-10 \mathrm{CA}$

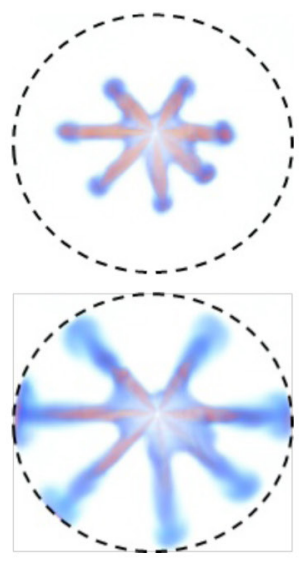

Vapor Fraction

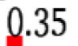

0.3

Figure 9. Volume rendering of in-cylinder temperature at SOC for different DE mixtures from piston bottom view 

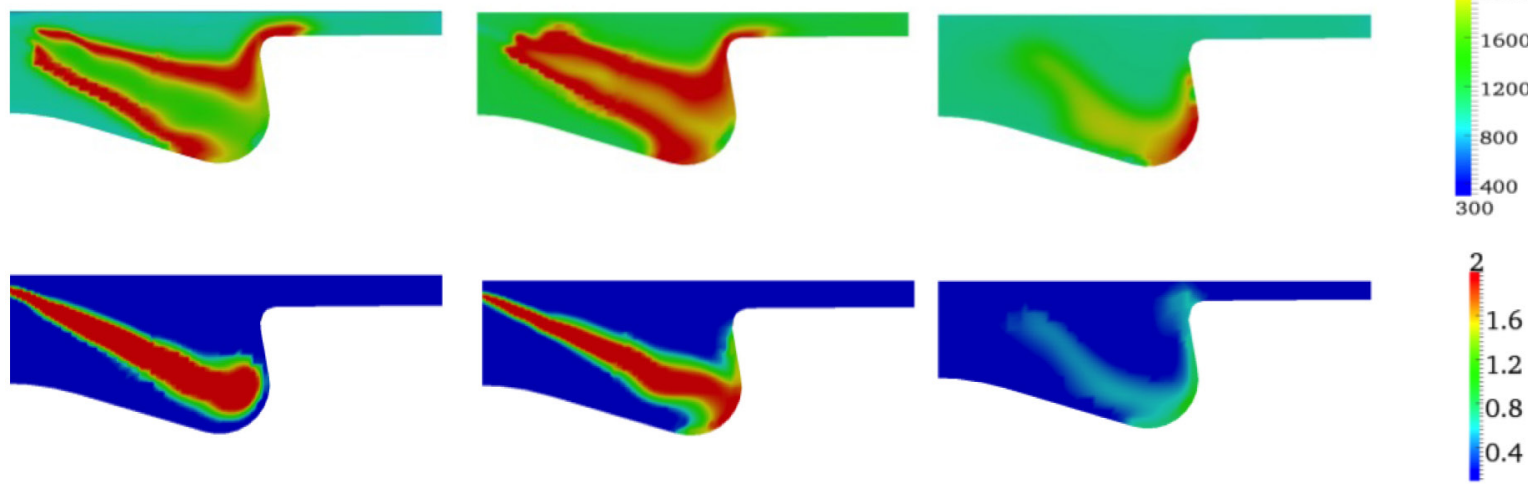

SOC (CA deg)

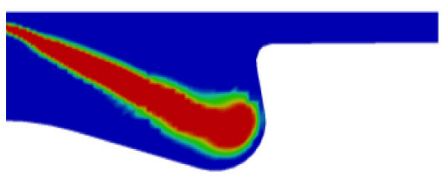

$-12$

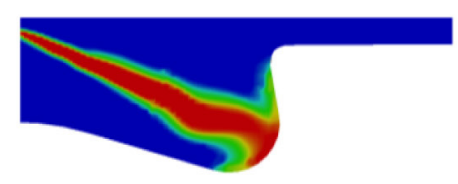

$-10$

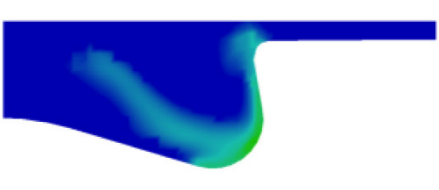

3

Figure 10. Temperature and $\varphi$ distribution cut-plane at SOC inside the domain with spray parcels in iso-metric view

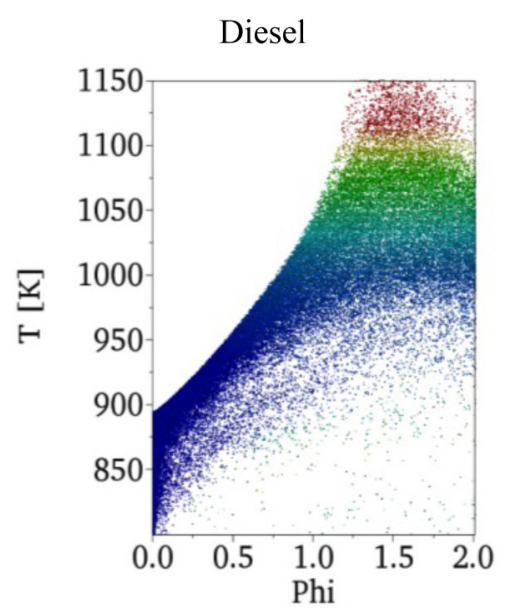

$\mathrm{SOC}=-12 \mathrm{CA}$
DE75

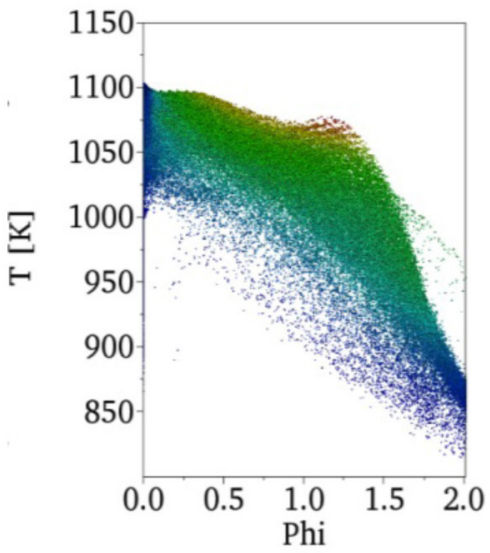

$\mathrm{SOC}=-10 \mathrm{CA}$
DE50

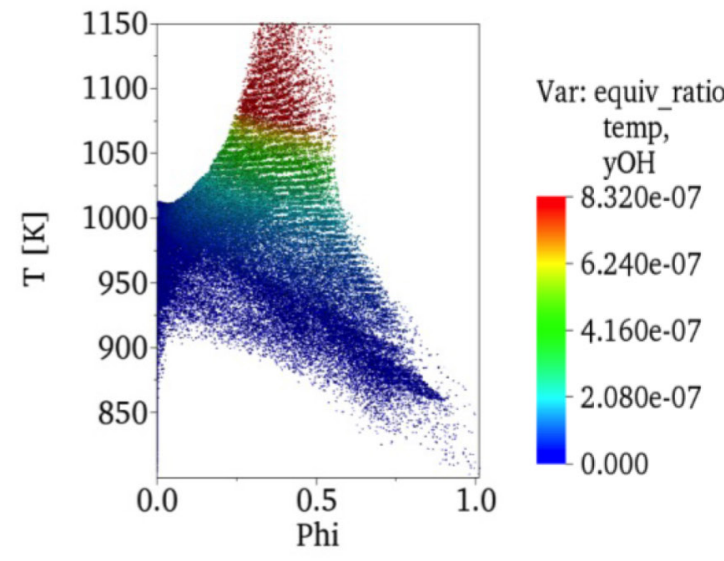

$\mathrm{SOC}=3 \mathrm{CA}$

Figure 11. T- $\varphi$ map of the cylinder at SOC colored with $\mathrm{OH}$ mass fraction

The temperature for all fuel is higher near the nozzle tip and as combustion progresses; higher temperature spreads towards the periphery. When the proportion of ethanol in DE mixture is increased, the in-cylinder temperature is decreased and this is attributed to the higher latent heat of vaporization of ethanol. The temperature distribution obtained for DE50 are lower when compared to diesel and DE75. The equivalence ratio $(\varphi)$ distribution is also examined to understand mixture distribution in combustion chamber. Equivalence ratio distribution inside the combustion domain for diesel reflects richer pockets compared to DE75, as seen from Figure 10. Although the ignition delay for diesel and DE75 are nearly the same, DE75 is leaner than diesel due to the fuel-bound oxygen within DEE and ethanol. The mixture tends to be leaner for DE50 and longer ignition delay further enhances the mixing. Thus, DE50 has nearly homogeneous mixing inside the cylinder domain, leading to $\mathrm{HCCI} /$ stratified type of combustion with lower temperature.

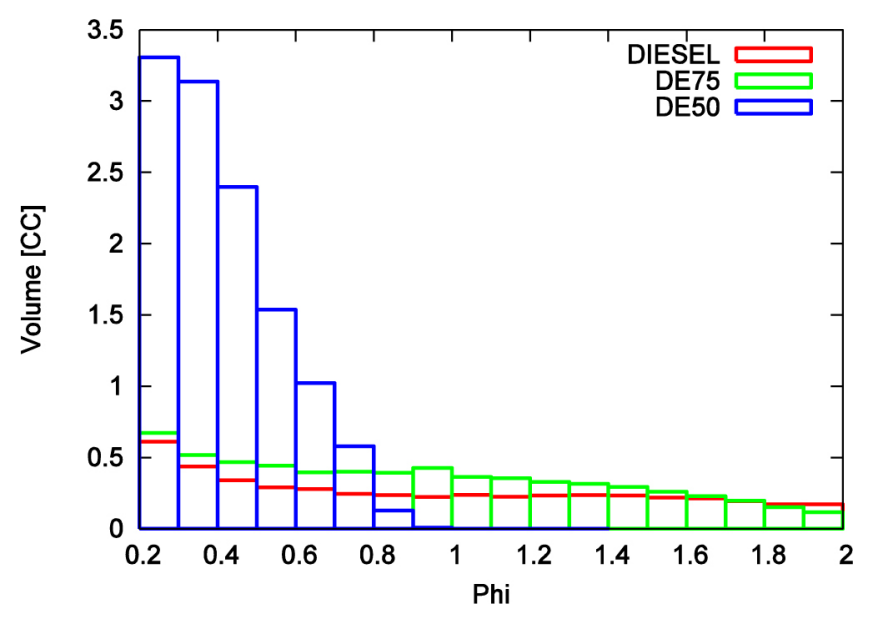

Figure 12. Volume and $\Phi$ histogram of bin width 0.1

The temperature and equivalence ratio distribution with $\mathrm{OH}$ mass fraction is plotted to further understand the combustion behavior of $\mathrm{DE}$ mixtures, as shown in Figure 11. Diesel shows ignition at $\varphi=1.2$ to 2 
(rich region) while DE75 show ignition at $\varphi=1$ to 1.5 (stoichiometry region). DE50 is different from diesel and DE75 in that ignition occurs at $\varphi=0.2$ to 0.5 (lean region), which shows that the mixture is lean overall and the combustion is similar to HCCI combustion. The equivalence ratio at start of ignition tends to decrease with the increase in proportion of ethanol in DEE and DE50 mixture turns lean to attain homogenous type of combustion. To verify the argument of HCCI or stratified type of combustion for DE50 mixture, the equivalence ratio distribution with volume at a bin width of 0.1 was plotted and shown in Figure 12. DE50 showed lean combustion behavior and more volume is accounted for $\varphi$ between 0.2 and 0.5 . Ignition occurs for DE75 in $\varphi$ range from 1 to 1.5 , which is near stoichiometric. Ignition is triggered for diesel in $\varphi$ range from 1.2 to 2 , which is obviously richer. The spray development process is gradual for DE mixtures, due to the lower viscosity, as evident from the spray tip penetration (Figure 5). Since spray advancement is less pronounced, air entrainment is reduced and the mixture is leaner for DE mixtures.

\section{Conclusions}

DEE, easily derived from ethanol, was used as a DCN improver for ethanol to promote auto-ignition in CI engine. DE mixtures were operated in a CI engine under diesel like fuel injection conditions (fuel injection timing $=-20 \mathrm{CAD}$ ). DE75 readily auto-ignited at ambient conditions like diesel, while DE50 ignited at an inlet air pressure of 1.5 bar. On the other hand, DE25 never showed autoignition at any range of inlet air pressure and temperature. From CI engine study, SOC for diesel and DE75 were comparable, while SOC was delayed for DE50. The peak in-cylinder pressure for diesel and DE75 were closer, whereas, there was $25 \%$ reduction for DE50 compared to diesel. The high reactivity of DEE supports the ignition of ethanol, while ethanol suppressed the auto-ignition of DEE due to its radical scavenging effect.

The physical and chemical effects on compression ignition of ethanol by DEE were further investigated by numerical simulations using CONVERGE. A combined mechanism for DEE and ethanol that captures the low temperature chemistry of DEE was developed. The developed model was reduced and validated against the engine experimental data. DE50 remained in vapor state from the point of fuel injection (-20 CAD) to $12 \mathrm{CAD}$ due to its lower DCN, while DE75 and diesel ignites earlier so that the vapor mass is zero before TDC. It was found that DEE and ethanol evaporate simultaneously in DE mixtures and therefore, chemical effects dominate the combustion. Diffusion combustion was evident for diesel; the temperature inside the combustion domain for diesel and DE75 were similar. Diesel ignited at $\varphi$ range between 1.2 and 2 (rich region), while DE75 ignited in the $\varphi$ range between 1 and 1.5 (stoichiometry region). However, DE50 ignited at $\varphi$ range between 0.2 and 0.5 (lean region) and the longer ignition delay due to chemical effects improved the fuel/air mixing process so as to decrease the average in-cylinder temperature. Thus, DE50 approached HCCI or PPCI at diesel like fuel injection conditions, which is remarkable.

Since DEE is a less viscous fuel with a higher vapor pressure, the fuel injection pressure was maintained at 300 bar in the current study. However, to operate DE mixtures in modern CI engine, the fuel injection pressure would be higher, which would impose certain problems related to cavitation. As such, the fuel injection system has to be changed accordingly. DME (dimethyl ether) injectors are available in the market to enable operation of DME in CI engines. Along the same lines, modification of fuel injection equipment for DEE could be pursued in the near future. Also, the effect of high reactivity of DEE on fuel storage and stability should be investigated. The present study initially focused on exploring the auto ignition of DE mixtures in an engine, and in the future, comprehensive fundamental and applied studies measuring other combustion characteristics should be performed.

\section{References}

1. Hansen, A. C., Zhang, Q., and Lyne, P. W., "Ethanol-diesel fuel blends--a review," Bioresource technology, 96:277-285, 2005, doi:10.1016/j.biortech.2004.04.007.

2. Giakoumis, E. G., Rakopoulos, C. D., Dimaratos, A. M., and Rakopoulos, D. C., "Exhaust emissions with ethanol or n-butanol diesel fuel blends during transient operation: a review," Renewable and Sustainable Energy Reviews, 17:170190, 2013, doi:10.1016/j.rser.2012.09.017.

3. Sayin, C., "Engine performance and exhaust gas emissions of methanol and ethanol-diesel blends," Fuel, 89:3410-3415, 2010, doi:10.1016/j.fuel.2010.02.017.

4. Li, D. G., Zhen, H., Xingcai, L., Wu-gao, Z., et. al., "Physicochemical properties of ethanol-diesel blend fuel and its effect on performance and emissions of diesel engines," Renewable energy, 30:967-976, 2005, doi:10.1016/j.renene.2004.07.010.

5. Sarathy, S.M., Oßwald, P., Hansen, N., and Kohse-Höinghaus, K.," Alcohol combustion chemistry," Progress in Energy and Combustion Science, 44:40-102, 2014, doi:10.1016/j. pecs.2014.04.003.

6. Leong, S. T., Muttamara, S., and Laortanakul, P., “Applicability of gasoline containing ethanol as Thailand's alternative fuel to curb toxic VOC pollutants from automobile emission," Atmospheric Environment, 36:3495-3503, 2002, doi: 10.1016/ $\underline{\mathrm{S} 1352-2310(02) 00288-1}$.

7. Schulz, M., and Clark, S., "Vehicle emissions and fuel economy effects of 16\% butanol and various ethanol blended fuels (E10, E20, and E85)," Journal of ASTM International, 8:1-19, 2011, doi:10.1520/JAI103068.

8. Jacobson, M. Z., "Effects of ethanol (E85) versus gasoline vehicles on cancer and mortality in the United States," Environmental Science \& Technology, 41:4150-4157, 2007, doi:10.1021/es062085v.

9. Roberts, M. C., "E85 and fuel efficiency: An empirical analysis of 2007 EPA test data," Energy Policy, 36:1233-1235, 2008, doi:10.1016/j.enpol.2007.11.006.

10. Agarwal, A. K., "Biofuels (alcohols and biodiesel) applications as fuels for internal combustion engines," Progress in energy and combustion science, 33:233-271, 2007, doi:10.1016/j. pecs.2006.08.003.

11. Xing-cai, L., Jian-Guang, Y., Wu-Gao, Z., and Zhen, H., "Effect of cetane number improver on heat release rate and emissions of high speed diesel engine fueled with ethanol-diesel blend fuel," Fuel, 83:2013-2020, 2004, doi:10.1016/j.fuel.2004.05.003. 
12. Shi, X., Pang, X., Mu, Y., He, H., et. al., "Emission reduction potential of using ethanol-biodiesel-diesel fuel blend on a heavy-duty diesel engine," Atmospheric Environment, 40:25672574, 2006, doi:10.1016/j.atmosenv.2005.12.026.

13. Can, Ö., Celikten, I., and Usta, N., "Effects of ethanol addition on performance and emissions of a turbocharged indirect injection diesel engine running at different injection pressures," Energy conversion and Management, 45:2429-2440, 2004, doi:10.1016/j.enconman.2003.11.024.

14. Rakopoulos, C. D., Antonopoulos, K. A., and Rakopoulos, D. C., "Experimental heat release analysis and emissions of a HSDI diesel engine fueled with ethanol-diesel fuel blends," Energy, 32:1791-1808, 2007, doi:10.1016/j.energy.2007.03.005.

15. Hulwan, D. B., and Joshi, S. V., "Performance, emission and combustion characteristic of a multicylinder DI diesel engine running on diesel-ethanol-biodiesel blends of high ethanol content," Applied Energy, 88:5042-5055, 2011, doi:10.1016/j. apenergy.2011.07.008.

16. Imran, A., Varman, M., Masjuki, H. H., and Kalam, M. A., "Review on alcohol fumigation on diesel engine: A viable alternative dual fuel technology for satisfactory engine performance and reduction of environment concerning emission," Renewable and Sustainable Energy Reviews, 26:739-751, 2013, doi:10.1016/j.rser.2013.05.070.

17. Vallinayagam, R., Vedharaj, S., Yang, W. M., Roberts, W. L., et. al., "Feasibility of using less viscous and lower cetane (LVLC) fuels in a diesel engine: A review," Renewable and Sustainable Energy Reviews, 51:1166-1190, 2015, doi:10.1016/j. rser.2015.07.042.

18. Rakopoulos, D. C., Rakopoulos, C. D., Kakaras, E. C., and Giakoumis, E. G., "Effects of ethanol-diesel fuel blends on the performance and exhaust emissions of heavy duty DI diesel engine," Energy Conversion and Management, 49:3155-3162, 2008, doi:10.1016/j.enconman.2008.05.023.

19. Karthikeyan, B., and Srithar, K., "Performance characteristics of a glowplug assisted low heat rejection diesel engine using ethanol," Applied Energy, 88:323-329, 2011, doi:10.1016/j. apenergy.2010.07.011.

20. Nagarajan, G., Rao, A. N., and Renganarayanan, S., "Emission and performance characteristics of neat ethanol fuelled Dl diesel engine," International journal of ambient energy, 23:149-158, 2002, doi:10.1080/01430750.2002.9674883.

21. Maurya, R. K., and Agarwal, A. K., "Experimental study of combustion and emission characteristics of ethanol fuelled port injected homogeneous charge compression ignition (HCCI) combustion engine," Applied Energy, 88:1169-1180, 2011, doi:10.1016/j.apenergy.2010.09.015.

22. Manente, V., Johansson, B., and Tunestal, P., "Characterization of partially premixed combustion with ethanol: EGR sweeps, low and maximum loads," Journal of Engineering for Gas Turbines and Power, 132:082802, 2010, doi:10.1115/1.4000291.

23. Manente, V., Tunestal, P., Johansson, B., and Cannella, W., "Effects of Ethanol and Different Type of Gasoline Fuels on Partially Premixed Combustion from Low to High Load," SAE Technical Paper 2010-01-0871, 2010, doi: 10.4271/2010-01$\underline{0871 .}$.
24. Westman, B., "Ethanol fuel in diesel engines for energy efficiency," Scania, 2005.

25. Munsin, R., Laoonual, Y., Jugjai, S., Matsuki, M., et. al., "Effect of glycerol ethoxylate as an ignition improver on injection and combustion characteristics of hydrous ethanol under CI engine condition," Energy Conversion and Management, 98:282-289, 2015, doi:10.1016/j.enconman.2015.03.116.

26. Aramsiriwat, R., Iempremjit, K., Munsin, R., Laoonual, Y. et al., "Classification of Startability Characteristics of a Compression Ignition Engine Fueled with Ethanol and Ignition Improvers," SAE Technical Paper 2015-01-0119, 2015, doi:10.4271/201501-0119.

27. Sorenson, S. C., "Dimethyl ether in diesel engines: progress and perspectives," Journal of Engineering for Gas Turbines and Power, 123:652-658, 2001, doi:10.1115/1.1370373

28. Bailey, B., Eberhardt, J., Goguen, S., and Erwin, J., "Diethyl Ether (DEE) as a Renewable Diesel Fuel," SAE Technical Paper 972978, 1997, doi:10.4271/972978.

29. Mack, J. H., Flowers, D. L., Buchholz, B. A., and Dibble, R. W., "Investigation of HCCI combustion of diethyl ether and ethanol mixtures using carbon 14 tracing and numerical simulations," Proceedings of the Combustion Institute, 30:2693-2700, 2005, doi:10.1016/j.proci.2004.08.136.

30. Qi, D. H., Chen, H., Geng, L. M., and Bian, Y. Z., "Effect of diethyl ether and ethanol additives on the combustion and emission characteristics of biodiesel-diesel blended fuel engine," Renewable Energy, 36:1252-1258, 2011, doi:10.1016/j. renene.2010.09.021.

31. ASTM D6890-15., "Standard Test Method for Determination of Ignition Delay and Derived Cetane Number (DCN) of Diesel Fuel Oils by Combustion in a Constant Volume Chamber," ASTM International, West Conshohocken, PA, 2015.

32. Cha, J., Yang, S., Naser, N., Ichim, A. et al., "High Pressure and Split Injection Strategies for Fuel Efficiency and Emissions in DI Diesel Engine," SAE Technical Paper 2015-01-1823, 2015, doi: 10.4271/2015-01-1823.

33. Rakopoulos, D. C., "Heat release analysis of combustion in heavy-duty turbocharged diesel engine operating on blends of diesel fuel with cottonseed or sunflower oils and their biodiesel," Fuel, 96:524-534, 2012, doi:10.1016/j.fuel.2011.12.063.

34. Rakopoulos, D. C., "Combustion and emissions of cottonseed oil and its bio-diesel in blends with either n-butanol or diethyl ether in HSDI diesel engine," Fuel, 105:603-613, 2013, doi:10.1016/j.fuel.2012.08.023.

35. Metcalfe, W. K., Burke, S. M., Ahmed, S. S., and Curran, H. J., "A hierarchical and comparative kinetic modeling study of C1C2 hydrocarbon and oxygenated fuels," International Journal of Chemical Kinetics, 45:638-675, 2013, doi:10.1002/kin.20802.

36. Mittal, G., Burke, S. M., Davies, V. A., Parajuli, B., et. al., "Autoignition of ethanol in a rapid compression machine," Combustion and Flame, 161:1164-1171, 2014, doi:10.1016/j. combustflame.2013.11.005.

37. Yasunaga, K., Gillespie, F., Simmie, J. M., Curran, H. J., et. al., "A multiple shock tube and chemical kinetic modeling study of diethyl ether pyrolysis and oxidation," The Journal of Physical Chemistry A, 114:9098-9109, 2010, doi:10.1021/jp104070a. 
38. Yasunaga, K., Simmie, J. M., Curran, H. J., Koike, T., et. al., "Detailed chemical kinetic mechanisms of ethyl methyl, methyl tert-butyl and ethyl tert-butyl ethers: The importance of uni-molecular elimination reactions," Combustion and Flame, 158:1032-1036, 2011, doi:10.1016/j.combustflame.2010.10.012.

39. Werler, M., Cancino, L. R., Schiessl, R., Maas, U., et. al., "Ignition delay times of diethyl ether measured in a highpressure shock tube and a rapid compression machine," Proceedings of the Combustion Institute, 35:259-266, 2015, doi:10.1016/j.proci.2014.06.143.

40. Cai, L., Sudholt, A., Lee, D. J., Egolfopoulos, F. N., et. al., "Chemical kinetic study of a novel lignocellulosic biofuel: Din-butyl ether oxidation in a laminar flow reactor and flames," Combustion and Flame, 161:798-809, 2014, doi:10.1016/j. combustflame.2013.10.003.

41. Al Rashidi, M. J., Davis, A. C., and Sarathy, S. M., "Kinetics of the high-temperature combustion reactions of dibutylether using composite computational methods," Proceedings of the Combustion Institute, 35:385-392, 2015, doi:10.1016/j. proci.2014.05.109.

42. Di Tommaso, S., Rotureau, P., Crescenzi, O., and Adamo, C., "Oxidation mechanism of diethyl ether: a complex process for a simple molecule," Physical Chemistry Chemical Physics, 13:14636-14645, 2011, doi:10.1039/C1CP21357A.

43. Kee, R. J., Rupley, F. M., and Miller, J. A., CHEMKIN-PRO 15112. Reaction Design, San Diego, CA.,

44. Lu, T., and Law, C. K., "Toward accommodating realistic fuel chemistry in large-scale computations," Progress in Energy and Combustion Science, 35:192-215, 2009, doi:10.1016/j. pecs.2008.10.002.

45. Reitz, R., and Diwakar, R., "Structure of High-Pressure Fuel Sprays," SAE Technical Paper $\underline{\text { 870598, }}$ 1987, doi: $10.4271 / 870598$.

46. Amsden, A. A., O'rourke, P. J., and Butler, T. D., KIVA-II: A computer program for chemically reactive flows with sprays (No. LA-11560-MS). Los Alamos National Lab., NM (USA), 1989.

47. Babajimopoulos, A., Assanis, D. N., Flowers, D. L., Aceves, S. M., et. al., "A fully coupled computational fluid dynamics and multi-zone model with detailed chemical kinetics for the simulation of premixed charge compression ignition engines," International journal of engine research, 6:497-512, 2005, doi:10.1243/146808705X30503.
48. Richards, K. J., Senecal, P. K., and Pomraning, E., "CONVERGE (Version 1.4.1) Manual," Convergent Science, Inc., Middleton, WI, 2012.

49. Golovichev V., Mechanisms, in, 2016.

50. Kodavasal, J., Kolodziej, C., Ciatti, S., and Som, S., "CFD Simulation of Gasoline Compression Ignition," ASME 2014 Internal Combustion Engine Division Fall Technical Conference, American Society of Mechanical Engineers, 2014.

51. Rakopoulos, D. C., Rakopoulos, C. D., Giakoumis, E. G., and Dimaratos, A. M., "Characteristics of performance and emissions in high-speed direct injection diesel engine fueled with diethyl ether/diesel fuel blends," Energy, 43:214-224, 2012, doi:10.1016/j.energy.2012.04.039.

52. Agarwal, A. K., and Chaudhury, V. H., "Spray characteristics of biodiesel/blends in a high pressure constant volume spray chamber," Experimental Thermal and Fluid Science, 42:212218, 2012, doi:10.1016/j.expthermflusci.2012.05.006.

53. Suh, H. K., and Lee, C. S., "Experimental and analytical study on the spray characteristics of dimethyl ether (DME) and diesel fuels within a common-rail injection system in a diesel engine," Fuel, 87:925-932, 2008, doi:10.1016/j.fuel.2007.05.051.

\section{Contact information}

Dr. Vedharaj Sivasankaralingam

Post-doctoral research fellow

Clean Combustion Research Centre (CCRC)

King Abdullah University of Science and Technology (KAUST)

Thuwal - , Saudi Arabia

vedharaj.sivasankaralingam $@$,kaust.edu.sa

Phone no - +966 542516245

\section{Acknowledgments}

This work was funded by competitive research funding from King Abdullah University of Science and Technology (KAUST) under the Clean Combustion Research Center's Future Fuels program. We also acknowledge funding from KAUST and Saudi Aramco under the FUELCOM program. Finally, we would like to express our gratitude to our Research Technician, Adrian. I. Ichim, for his support in carrying out the engine experiments at KAUST engine lab.

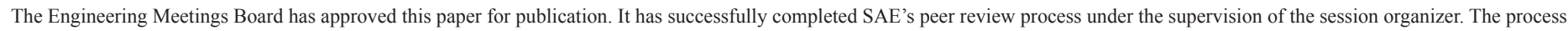
requires a minimum of three (3) reviews by industry experts.

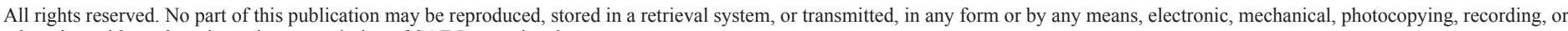
otherwise, without the prior written permission of SAE International.

Positions and opinions advanced in this paper are those of the author(s) and not necessarily those of SAE International. The author is solely responsible for the content of the paper.

ISSN 0148-7191

http://papers.sae.org/2016-01-2180 